\title{
Analysis of the Effects of Snowpack Properties on Satellite Microwave Brightness Temperature and Emissivity Data \\ Tarendra Lakhankar ${ }^{1 *}$, Amir E Azar ${ }^{1}$, Narges Shahroudi ${ }^{1}$, Alfred Powell ${ }^{2}$ and Reza Khanbilvardi ${ }^{1}$
}

${ }^{1}$ NOAA-Cooperative Remote Sensing Science \& Technology Center (NOAA-CREST), City University of New York, NY 10031 USA

${ }^{2}$ National Environmental Satellite Data and Information Service (NOAA/NESDIS/STAR), Camp Springs, MD20746 USA

\begin{abstract}
Spatial variations of snowpack properties are an essential component in flood predictions and water resource management. Satellite microwave remote sensing has shown great potential in retrieving snowpack properties such as: snow depth, snow grain size, and snow density. In this research, we investigate the potential of microwave emissivity which is highly influenced by snowpack properties. Brightness temperature and emissivity data generated from HUT (Helsinki University of Technology) microwave emission of snow model were evaluated with satellite microwave measurements. The comparison of the real measurements (in-situ and satellite) with the modeled results shows that the scattering signature $(19 \mathrm{GHz}-37 \mathrm{GHz}$ and $19 \mathrm{GHz}-85 \mathrm{GHz}$ ) shows better results in emissivities rather than brightness temperature data. Furthermore, the over the deep snow $(>30 \mathrm{~cm})$, the emissivities scattering signature of $(19 \mathrm{GHz}$ $37 \mathrm{GHz})$ has best performance while over shallow snow $(<30 \mathrm{~cm})$ the emissivities scattering signature of $(19 \mathrm{GHz}-$ $85 \mathrm{GHz}$ ) performs superior. The results indicate the validity of grain growth assumption to some extent but it fails to address it quantitatively as a function of time.
\end{abstract}

Keywords: Snowpack; Passive microwave; Remote sensing; Snow emission model

\section{Introduction}

According to the Federal Emergency Management Agency (FEMA), floods are one of the most common hazards in the United States. A reanalysis of the National Weather Service (NWS) estimates of flood damage in the United States, showed that flood damage continues to be a concern despite local and federal efforts to mitigate floods [1]. One of the most common reasons for floods is rainfall on snow covered areas. Snowpack is a complex medium with large spatial and temporal variability, which consist of several layers with different densities and grain size distributions. Snow Water Equivalent (SWE), the volume of liquid water present in the snowpack is a function of snow depth and snow density used in hydrological modeling.

During the melting season precipitation tends to occur in the form of rain rather than snow. When rain accompanies melting snow, the melting process is accelerated due to warm temperature, causing difficulty in quantify snow-melt water from snow, results in unpredicted flooding [2]. Therefore, an adequate knowledge of snowpack properties is necessary for use in hydrological, meteorological, and hydroclimatological models for flood analysis, weather forecasting, and water resource management $[2,3]$.

The launch of earth observatory satellites in the mid-twentieth century and their capability to observe the earth on large scales enabled the meteorologists and hydrologists around the world to find alternatives methods of estimating snowpack properties. For decades, visible satellite sensors such as Land Remote Sensing Satellite (LANDSAT), Multi-spectral Scanner (MSS), and LANDSAT Thematic Mapper (TM) were monitoring the Northern Hemisphere. But visible satellite sensors can detect snow cover only during cloud-free daylight condition without providing any information of snow depth. Contrary to the visible band, microwaves can pass through precipitating clouds due to the fact that they have long wavelengths.

The satellite microwave sensors such as: Scanning Multichannel Microwave Radiometer (SMMR), Special Sensor Microwave Imager (SSM/I), and Advanced Microwave Scanning Radiometer-Earth Observing System (AMSR-E) shown great potential to estimate snow depth or SWE. The multiple channels and spectral difference on these microwave sensors permitted better detection of the land covered by snow. Several research studies used the combination of 19, 37 and 85/89 $\mathrm{GHz}$ microwave frequencies for estimation of snow depth and snow water equivalent [4-8].

Microwave radiation responds to snow properties such as density, depth, grain size, temperature, surface wetness, melting-refreezing cycles, and vegetation $[9,10]$. Most of the algorithms used for estimating snowcover from spaceborne microwave radiometers are empirical formulas [4,8,11-14]. These algorithms are restricted because they use regional empirical regression coefficients. Another approach to estimate snowpack properties with microwaves is to develop inversion techniques in emission models. The benefit of the emission models is that the use of empirical coefficients can be avoided. Several models have been proposed in the literature to describe the relationships between snow parameters such as mean grain size, density, snow depth and electromagnetic quantities [15-17].

In this study, a microwave emission model developed by Helsinki University of Technology (hereafter referred as HUT model) is used. HUT model is semi-empirical model which combines theory with results from measurements. The objective of this study is to investigate the potential of emissivity data in improving estimation of snowpack properties (snow depth, snow grain size and snow density) which are essential components in flood forecasting. The sensitivity of snow

${ }^{*}$ Corresponding author: Tarendra Lakhankar, NOAA-Cooperative Remote Sensing Science \& Technology Center (NOAA-CREST), City University of New York, NY 10031 USA, Tel: +1-212-650-5815; Fax: +1-212-650-8097; E-mail: tlakhankar@ccny.cuny.edu

Received December 16, 2011; Accepted February 07, 2012; Published February 09, 2012

Citation: Lakhankar T, Azar AE, Shahroudi N, Powell A, Khanbilvardi R (2012) Analysis of the Effects of Snowpack Properties on Satellite Microwave Brightness Temperature and Emissivity Data. J Geophys Remote Sensing 1:101. doi:10.4172/ 2169-0049.1000101

Copyright: (c) 2012 Lakhankar T et al. This is an open-access article distributed under the terms of the Creative Commons Attribution License, which permits unrestricted use, distribution, and reproduction in any medium, provided the original author and source are credited. 
parameters to brightness temperature and emissivity of different SSM/I frequencies $(19,37,85 \mathrm{GHz})$ and their scattering signatures were investigated. Then, we compared the performance of brightness temperature and emissivity data in estimating snowpack properties (snow depth and grain size) using HUT model. At the end, we derive and qualitatively evaluate the time-series of snowpack properties estimated by brightness temperature and emissivity.

\section{Study Area}

The study area is in the Great Plains of the northern United States and southern Canada, located between $45 \mathrm{~N}-52 \mathrm{~N}$ and $96 \mathrm{~W}-114 \mathrm{~W}$ including, North Dakota, South Dakota, Western Minnesota, Eastern Montana, Sothern Alberta, Saskatchewan, and Manitoba (Figure 1). The Great Plains have a long history of snow-melt related floods. The Red River has a long history of snow melt floods, including another significant event in 2011.

The northern Great Plains is an ideal location for the development of passive microwave snowpack algorithms. The region has relief on the scale of the passive microwave sensors, $25 \mathrm{~km}$ to $50 \mathrm{~km}$, and consists mostly of open prairie or farmland. Wintertime temperatures are generally quite cold for extended periods of time, which limits meltfreeze effects. The snowpack in this area is less than $1 \mathrm{~m}$ deep; moderately cold; subject to wind drifting; and contains large annual variations and spatial variations on length scales of tens of kilometers [18].

\section{Datasets}

\section{Brightness temperature}

Satellite microwave data from Special Sensor Microwave Imager (SSM/I) are used in this study. This polar orbiter satellite observes the Earth twice daily at four frequencies $(19,22,37$, and $85 \mathrm{GHz})$ at vertical and horizontal ( $\mathrm{H}$ and $\mathrm{V}$ ) polarizations, with the exception of $22 \mathrm{GHz}$, which is vertical polarization only. The observing incidence angle is close to $53^{\circ}$, and the fields of view decrease from $43 \mathrm{~km} \mathrm{x} 69 \mathrm{~km}$ to $13 \mathrm{~km} \times 15 \mathrm{~km}$ [19]. Brightness temperature data are obtained from National Snow and Ice Data Center (NSIDC) in $25 \mathrm{~km}$ x $25 \mathrm{~km}$ spatial resolution (EASE-GRID format).

\section{Emissivity}

Brightness temperature measured by satellites is a function of land emissivity and surface/skin temperature. By removing the contribution of surface temperature, the land emissivities have higher potential

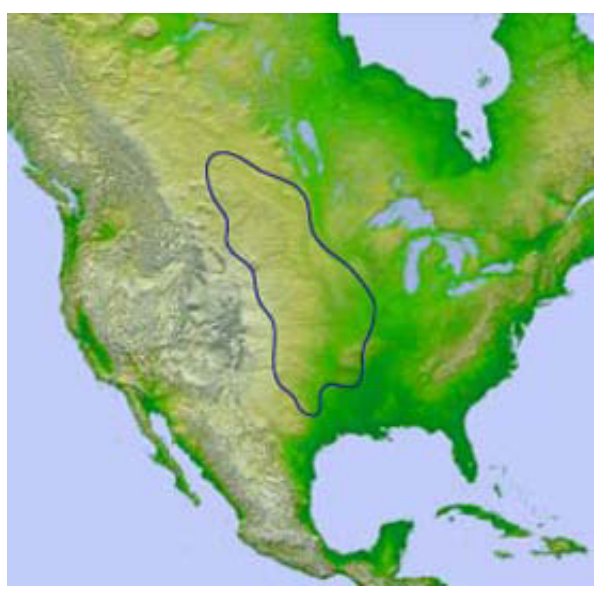

Figure 1: Study area marked by line includes Great Plains of the northern United States and southern Canada (Source: www.missouri.edu/). to monitor changes in snow properties. Microwave emissivities are estimated from SSM/I observations by removing the contributions of the atmosphere, clouds, and rain using ancillary data from International Satellite Cloud Climatology Project (ISCCP). Cloud-free SSM/I observations are first isolated with the help of collected visible/infrared satellite observations. Then the cloud-free atmospheric contribution is calculated from an estimate of the local atmospheric temperaturehumidity profile (National Centers for Environmental Predication (NCEP) analyses). Finally, with the surface skin temperature derived from IR observation (ISCCP estimate), the surface emissivity was calculated for all the SSM/I channels [20].

\section{Ground measurement}

In the Northern Great Plains region, National Climate Data Center (NCDC) in the USA and National Climate Data and Information Archive operated by Environment Canada make daily weather observations of temperature, precipitation, snowfall, and snowpack thickness. In this study, 28 stations in the USA and Canada were chosen to be used as the emission model input for comparing the snowpack properties variations with the pattern found in SSM/I observations. The ground stationed data were selected during mid-winter period of season 2003-2004 as an input to the HUT model for sensitivity analysis. It should be noted that the mid-winter snow depth are significantly stable with lower variation (smaller standard deviation) in snow depth. However, in early winter due to snowfall discontinuation and melting and refreezing during late winter tends to produces larger variation in snow depth at the satellite (SSM/I) pixel resolution [21].

\section{Snow emission model}

The HUT snow microwave emission model is a semi-empirical approach based on radiative transfer was developed by Pulliainen in 1999 at Helsinki University of Technology [17]. The HUT model assume the snow cover as a single homogeneous layer and the emission from the snow cover is a function of snow depth, snow density, snow grain size, snow temperature and, in the wet snow case, surface roughness of the air and snow boundary, and snow wetness. The radiative transfer equation estimating brightness temperature at depth $(d)$ and incidence angle $(\theta)$ is given by:

$$
\begin{aligned}
& T_{B}\left(d^{-}, \theta\right)=T_{B}\left(0^{+}, \theta\right) \cdot e^{-\left(k_{e}-q k_{s}\right) \sec \theta d} \\
& +\frac{k_{a} T_{s}}{k_{e}-q k_{s}}\left(1-e^{-\left(k_{e}-q k_{s}\right) \sec \theta d}\right)
\end{aligned}
$$

Where, $T_{B}=$ brightness temperature; $T_{s}=$ physical snow temperature, $k_{a}=$ absorption coefficient $k_{s}=$ scattering coefficient; $k_{e}=$ extinction coefficient. The first term in above equation is brightness temperature contribution from soil surface below snow layer and attenuated by snow layer. The second term is brightness temperature contribution from homogeneous snow layer. Thus, the model takes into account the emission emitted downward and reflected upward from the snow and soil boundary. The extinction coefficient is function of snow grain size. The absorption coefficient is function of snow dielectric properties of snow layer. More detailed description can be found at [17]. To calculate this emission, the rough bare soil reflectivity model developed at the University of Bern, Switzerland was used [22]. The dielectric constant of the soil was chosen to be $3.5+.1 \mathrm{j}$ from $[23,24]$. The basic assumption in the HUT model is that scattering is mostly concentrated in the forward direction. The passive microwave data and ground measurements 
were used as inputs to the model to calculate variations of snowpack properties spatially and temporally.

\section{Methodology}

As discussed before, different land parameters and snow properties influence the microwave emissions. In a simplified format, brightness temperature recorded by satellite's sensor is influenced by land characteristics, surface temperature, snow depth, snow density, and snow grain size. Assuming the land characteristics do not change during the season, the changes in microwaves measured by satellite should originate from changes in snowpack properties. These changes range from snowfall (depth increase) to snow melt (depth decrease) as well as snow metamorphic evolutions.

In the initial stage of this study, we investigated the sensitivity of brightness temperature and emissivity of different SSM/I frequencies to snow parameters $(19,37,85 \mathrm{GHz})$ and their vertical and horizontal polarized scattering signatures. The HUT model was fed with a constant density, temperature, grain size range, and snow depth to understand the variation of grain size versus snow depth brightness temperature and emissivity.

In the second stage, we evaluated the performance of brightness temperature and emissivity data. Using ground measurements of snow depth along with the HUT model we verified the channels and their scattering signatures have the highest potential in estimating snowpack properties (snow depth, density, and grain size).

Finally, the time-series of snowpack properties changes over 28
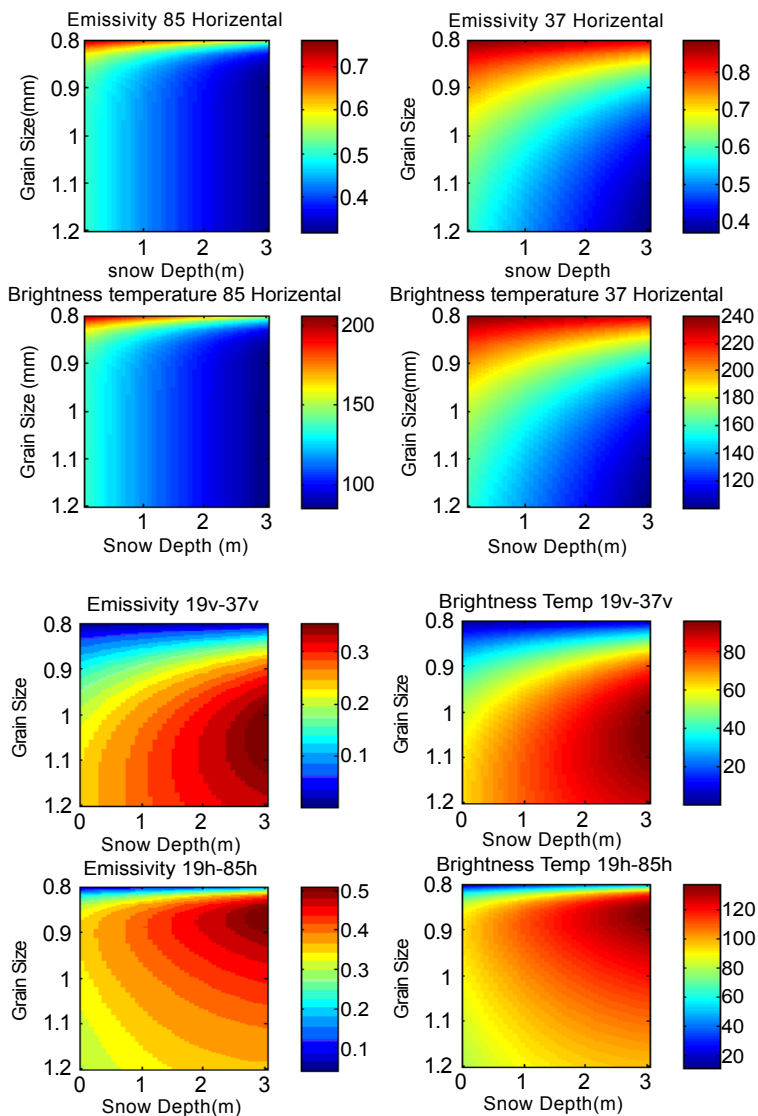

Figure 2: Variation of brightness temperature and emissivity versus snow depth and grain size for (a) $37 \mathrm{H}$ and $85 \mathrm{H}$, and (b) $19 \mathrm{~V}-37 \mathrm{~V}$ and $19 \mathrm{H}-85 \mathrm{H}$.
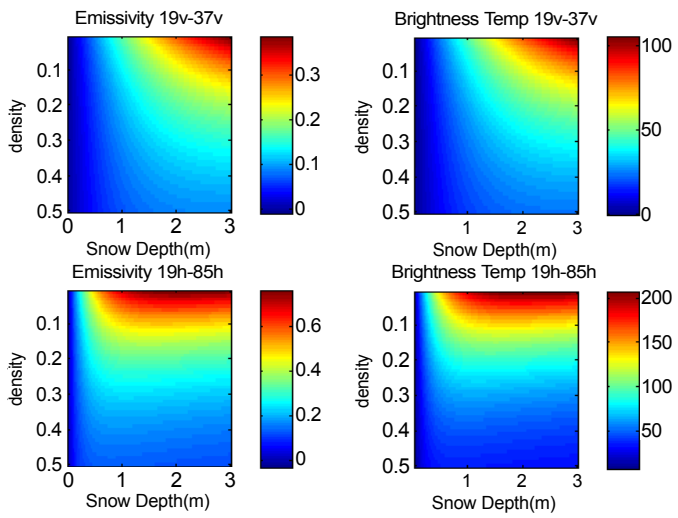

Figure 3: Variation of brightness temperature and emissivity versus snow depth and density for $19 \mathrm{~V}-37 \mathrm{~V}$ and $19 \mathrm{H}-85 \mathrm{H}$.

stations within the study area were derived. The time-series was used for monitoring and evaluation of changes in snow properties during winter season 2003-2004.

\section{Results and Discussion}

\section{Sensitivity analysis and performance in different microwave bands}

In order to analyze the sensitivity of microwave brightness temperature and emissivity to different snow parameters, the HUT model was again used as the basis of comparison. Initially the input consisted of: constant density and temperature, a range of grain size $(0.8-1.2 \mathrm{~mm})$ and a range snow depth $(0-3 \mathrm{~m})$. The output consisted of model produced brightness temperature and emissivities. Then the grain size was assumed a constant in the density range $\left(0.01-0.41 \mathrm{~g} / \mathrm{cm}^{3}\right)$ and was used in the model to show the variation of density versus snow depth and emissivity/brightness temperature. Figure 2a,b illustrate the results for both brightness temperature and emissivity data for a snowpack with density of $0.3 \mathrm{~g} / \mathrm{cm}^{3}$. It is shown that channel $85 \mathrm{GHz}$ (Figure 2a) and the scattering signatures of $19 \mathrm{GHz}-85 \mathrm{GHz}$ (Figure 2b) in both polarizations are highly sensitive to the changes in snow depth and grain size.

In other words, in the $85 \mathrm{GHz}$ channel, brightness temperature and emissivity show high dependency to variations in snow depth and grain size. The sensitivity decreases where snow depth and grain size increase and pass a certain threshold. For instance, given a density of $0.3 \mathrm{~kg} / \mathrm{cm}^{3}$, the $85 \mathrm{GHz}$ channel and the scattering signatures of $19 \mathrm{GHz}-85 \mathrm{GHz}$ are not capturing the increase of depth after $25 \mathrm{~cm}$. On the other hand, for deeper snow, the $37 \mathrm{GHz}$ channel (Figure 2a) and the scattering signatures of $19-37 \mathrm{GHz}$ channel (Figure $2 \mathrm{~b}$ ) show more sensitivity where the snow depth is higher than $25 \mathrm{~cm}$.

Similar behavior is observed between density, depth, and microwave scattering for a given grain size (Figure 3). Increases in density and depth increase the microwave scattering. Again, the sensitivity of microwaves is greater in the high frequency band of $85 \mathrm{GHz}$. This analysis indicates that the $85 \mathrm{GHz}$ and $37 \mathrm{GHz}$ channels have the potential for estimating the snowpack properties of density and grain size but will be limited by the snow depth. To reach the optimum answer in the retrieval, all snowpack characteristics must be solved simultaneously.

\section{Comparison of brightness temperature and emissivities}

The major difference between brightness temperature and 

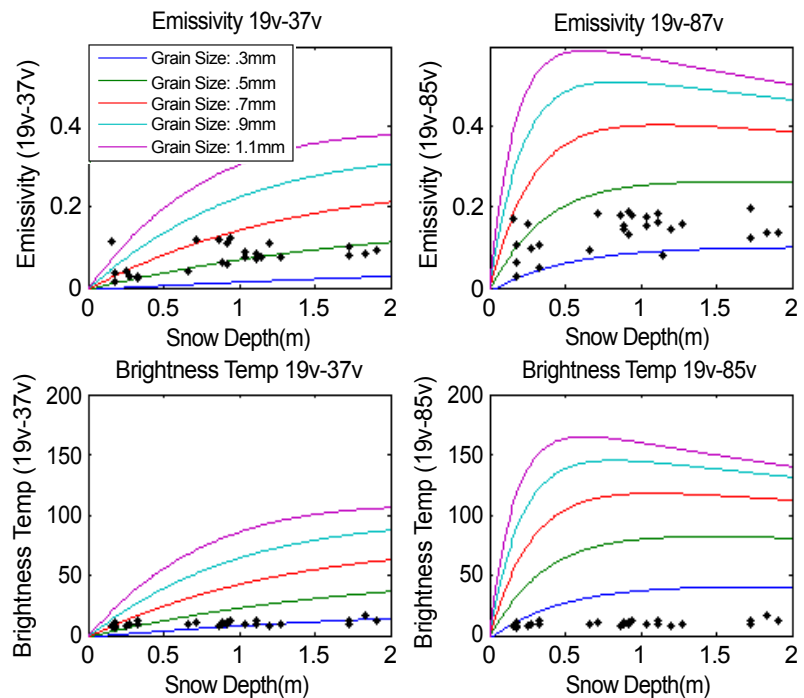

Emissivity 19v-37v

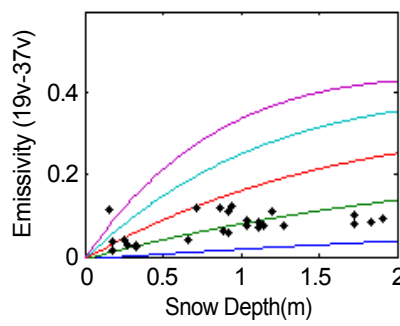

Snow Depth $(m)$
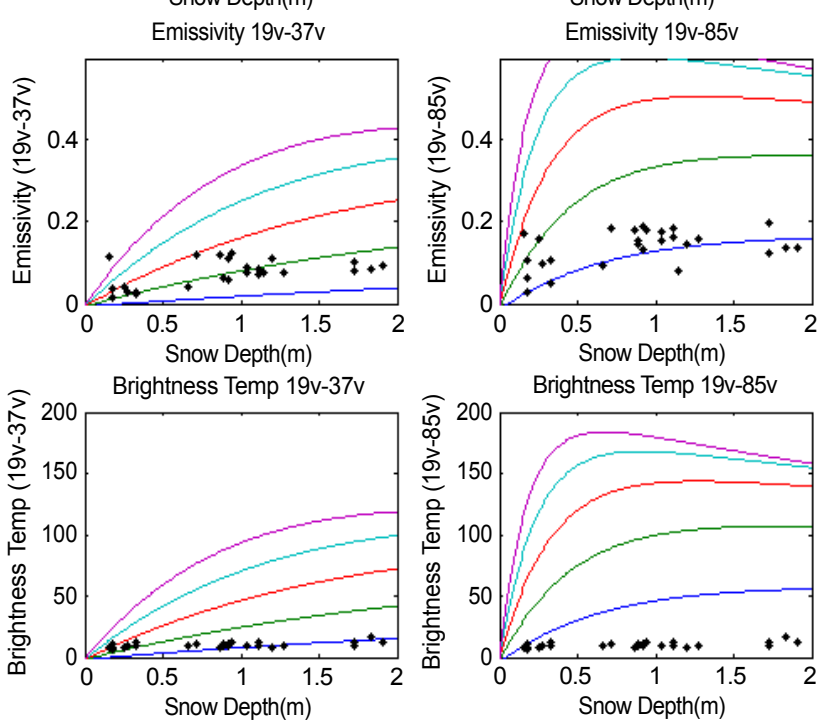

Figure 4: Measured and modeled snow depth and the corresponding brightness temperature and emissivity at assumed density (a) $0.3 \mathrm{~g} / \mathrm{cm}^{3}$, (b) $0.2 \mathrm{~g} / \mathrm{cm}^{3}$.

emissivity is the skin temperature. In the emissivity, the effect of skin/surface, temperature and atmosphere/cloud are filtered out of brightness temperature [20]. The use of emissivities can potentially reduce the error originating from the effect of temperature in snow estimations. In this section, first we used HUT model to produce the graphs that show the effect of snow depth and snow grain size changes on brightness temperature and emissivities. Then, we superimposed to the graph the points corresponding to satellite-measured brightness temperature or emissivity for ground measured snow depth. Each of the points represents a certain day and location.

A comparison of the performance of emissivity versus brightness temperature are shown in Figure 4a,b. The snow depth data are reported from the ground stations and the brightness temperature and emissivities are measured by satellite's sensor. The black points on the graphs represent the ground measured snow depths and their corresponding satellite brightness temperature, emissivity measurements for various locations. The curves are model-produced brightness temperature and emissivity for various snow depth and grain size.
Looking into (Figure $4 \mathrm{a})$, where snow density is assumed ( $0.3 \mathrm{~g} /$ $\mathrm{cm}^{3}$ ), couple of characteristics are observed. First, the graphs that are derived based on emissivity data (Figure 4a), show better relations between measured and modeled snow properties. The black points that represent measured snow depth and microwaves are along with the modeled grain sizes of $0.3-0.7 \mathrm{~mm}$ which is a reasonable range for
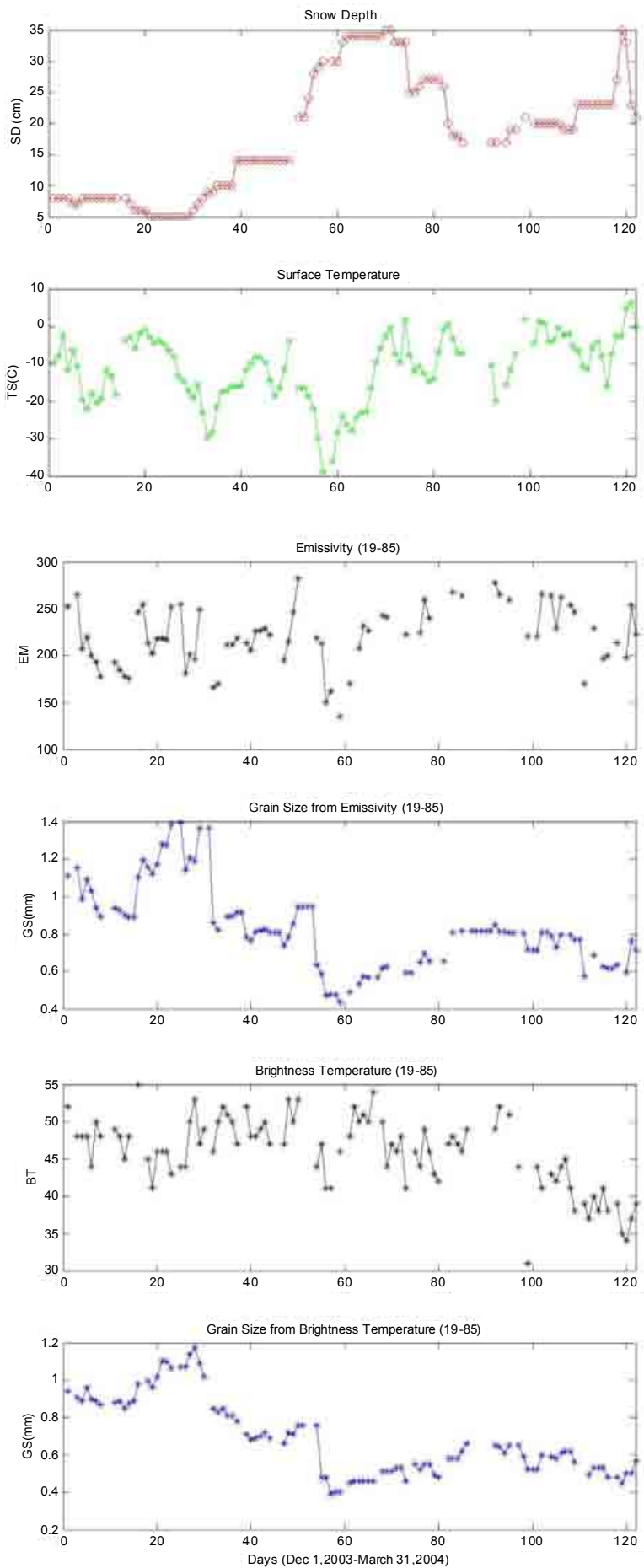

Figure 5: Time series of derived grain size (GS), snow depth (SD), snow temperature (TS), brightness temperature (BT), and emissivity (EM) of $19 \mathrm{~V}-85 \mathrm{~V}$ at station (Lat: 53.31 and Long: 113.56). 

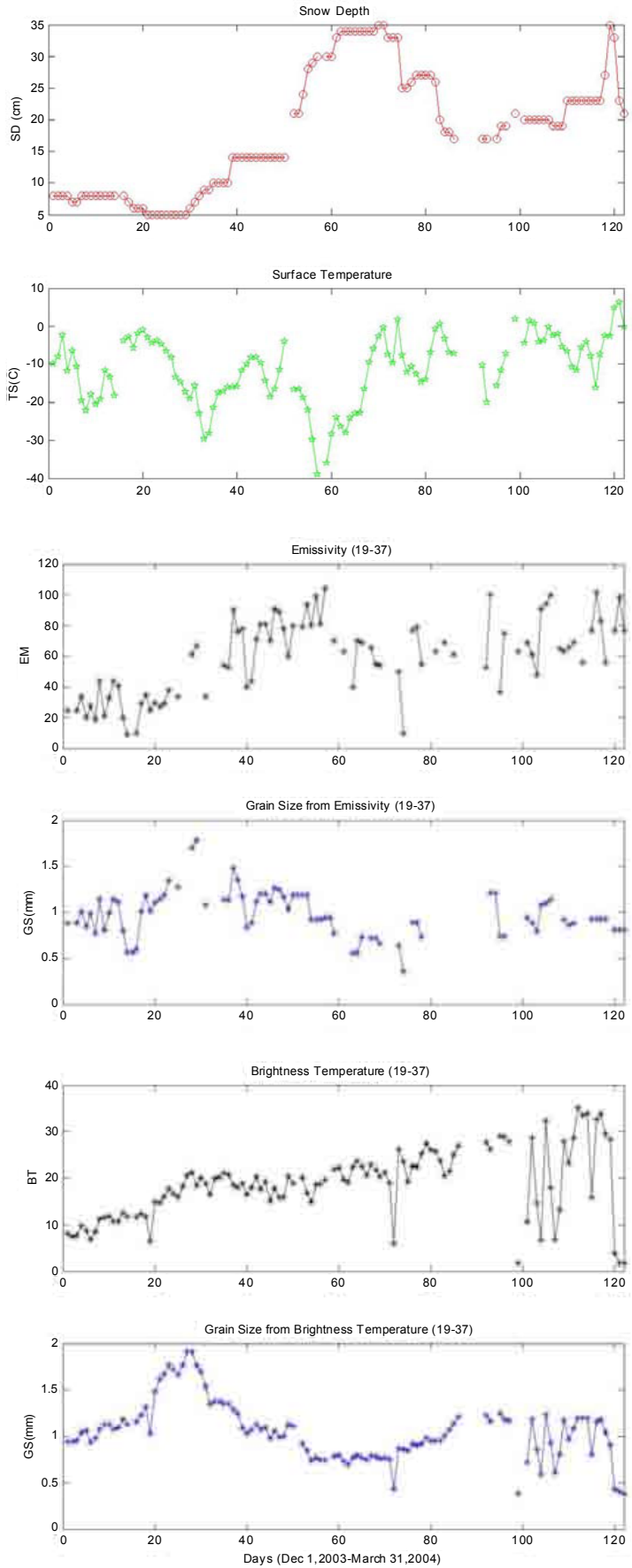

Figure 6: Time series of derived grain size (GS), snow depth (SD), snow temperature (TS), brightness temperature (BT), and emissivity (EM) of $19 \mathrm{~V}-37 \mathrm{~V}$ at station (Lat: 53.31 and Long: 113.56).

snow grain size [25]. On the other hand, the graphs based on brightness temperature show very weak performance since the average snow grain size becomes too small $(>0.3 \mathrm{~mm})$ and cannot be correct. Second, over the shallow snow $(<30 \mathrm{~cm})$, the scattering signature of $(19 \mathrm{~V}-85 \mathrm{~V})$ shows a wider range for grain size $(0.3-0.7 \mathrm{~mm})$ while for deeper snow, this signature shows grain range between $0.3-0.5 \mathrm{~mm}$. Given the fact that snow grain size should increase for deeper snowpack, the performance of the $(19 \mathrm{~V}-85 \mathrm{~V})$ signature weakens for deeper snow. Over the deep snow the emissivity scattering signature of $(19 \mathrm{~V}-37 \mathrm{~V})$ shows the highest performance (Figure 4a). Similar behavior is observed for a snow with assumed density of $0.2 \mathrm{~g} / \mathrm{cm}^{3}$ (Figure $4 \mathrm{~b}$ ).

The comparison of the real measurements (ground and satellite) with the modeled results shows that the scattering signature $(19 \mathrm{GHz}-$ $37 \mathrm{GHz}$ and $19 \mathrm{GHz}-85 \mathrm{GHz}$ ) shows better results in emissivities rather than brightness temperature data. The emissivities derived from channel differences $(19 \mathrm{GHz}-37 \mathrm{GHz}$ and $19 \mathrm{GHz}-85 \mathrm{GHz})$ for all densities produce grain sizes between $0.3 \mathrm{~mm}-0.7 \mathrm{~mm}$ and for brightness temperature a grain size range between $0-0.3 \mathrm{~mm}$ which is cannot be correct. This confirms the fact that atmospheric effects influencing the brightness temperature data will increase the error and that using emissivity data produces better results. Furthermore, the over the deep snow $(>30 \mathrm{~cm})$, the emissivities scattering signature of $(19 \mathrm{GHz}-37 \mathrm{GHz})$ has the best performance.

\section{Time-series of snowpack properties, brightness temperature and emissivity data}

In this approach, we investigate the seasonal behavior of derived snow grain size from the model using the measured snow depth, measured surface temperature, constant density, and the brightness temperature/emissivity data from the satellite as inputs of the model. Generally, snow grain size tends to increase during the winter season [26]. The aged snow average grain size could be three to four times larger than the fresh snow. The question is whether this fact can be used to quantitatively define a seasonal behavior for snow grain size. Figure 5 and Figure 6 illustrate the behavior of the derived snow grain size with respect to snow depth, surface temperature, and SSM/I brightness temperature and emissivity for the whole winter season (Dec 1, 2003Mar 31, 2004) at station 10 (Lat:53.31 and Lon: 113.56).

Snow grain size at surface level is lower than snow layer near soil surface. This can be related to fresh snow on surface layer. Fresh snow has smaller grains which reduces the average grain size of the snowpack. Snow grain size derived from the model using the emissivity behaves the same for both channels ( 37 and $85 \mathrm{GHz}$ ). Snow grain size derived from the model using the brightness temperature for both channels follow the same pattern as the ones from the emissivity only with a smaller grain size range. The results indicate the validity of grain growth assumption to some extent but it fails to address it quantitatively as a function of time.

\section{Conclusion}

This study explored the potential of satellite microwave emissivity and brightness temperature data in estimating snow properties (snow depth, grain size and snow density). The results from using brightness temperature and emissivity at different frequencies and polarization were analyzed and compared. Variations of snow grain size, density, and frequency were derived from the model and compared with different channel brightness temperature and emissivities.

The modeled data and real measurements (ground and satellite) comparison at scattering signature $(19 \mathrm{GHz}-37 \mathrm{GHz}$ and $19 \mathrm{GHz}-$ $85 \mathrm{GHz}$ ) shows better results using emissivities rather than brightness temperature data. The emissivities derived from channel differences for all densities produce grain sizes between $0.3 \mathrm{~mm}-0.7 \mathrm{~mm}$ and for brightness temperature a grain size range between $0-0.3 \mathrm{~mm}$ which is cannot be correct. This confirms the fact that atmospheric effects influencing the brightness temperature data will increase the error and that using emissivity data produces better results. Furthermore, the over the deep snow $(>30 \mathrm{~cm})$, the emissivities scattering signature of 
Citation: Lakhankar T, Azar AE, Shahroudi N, Powell A, Khanbilvardi R (2012) Analysis of the Effects of Snowpack Properties on Satellite Microwave Brightness Temperature and Emissivity Data. J Geophys Remote Sensing 1:101. doi:10.4172/2169-0049.1000101

$(19 \mathrm{GHz}-37 \mathrm{GHz})$ shows better performance.

In time-series analysis of snow properties and microwaves, we observed that the average snow grain size decreases when snow depth increases due to fresh snowfall at top layer. Fresh snow has a smaller grain size. Thus reduce the average grain size of snowpack layer. The increase in the snow grain size near soil layer can be associated with snow metamorphism. When snow melts the processes of metamorphism accelerates increasing the size of the snow grains.

\section{Acknowledgment}

This study was supported and monitored by National Oceanic and Atmospheric Administration (NOAA) under Grant NA06OAR4810162, NA08NES4280027 and NA11SEC4810004. The views, opinions, and findings contained in this report are those of the author(s) and should not be construed as an official National Oceanic and Atmospheric Administration or U.S. Government position, policy, or decision. The authors would like to acknowledge NOAA-CREST, NOAA/NESDIS for support and thank Prof. Pulliainen from Helsinki University of Technology for providing the HUT model and some of the computer codes.

\section{References}

1. Pielke RA Jr, Downton MW, Miller JZB (2002) Flood Damage in the United States, 1926-2000: A Reanalysis of National Weather Service Estimates. UCAR: Boulder, Colorado.

2. McCabe GJ, Hay LE, Clark MP, (2007) Rain-on-Snow Events in the Western United States. Bulletin of the American Meteorological Society 88: 319-328.

3. Papa F, Prigent C, Rossow WB (2007) Ob' River flood inundations from satellite observations: A relationship with winter snow parameters and river runoff. J Geophys Res 112: 1-11.

4. Chang ATC, Foster JL, Hall DK (1987) Nimbus-7 SMMR derived global snowcover parameters. Annals of Glaciology 9: 39-44.

5. Chang ATC, Foster JL, Hall DK, Rango A, Hartline BK (1982) Snow wate equivalent estimation by microwave radiometry. Cold Regions Science and Technology 5: 259-267.

6. Foster JL, Chang ATC, Hall DK (1997) Comparison of snow mass estimates from a prototype passive microwave snow algorithm, a revised algorithm and a snow depth climatology. Remote Sensing of Environment 62: 132-142.

7. Grody NC, Basist AN (1996) Global identification of snowcover using SSM/l measurements. IEEE Trans Geosci Remote Sens 34: 237-249.

8. Kelly RE, Chang AT, Leung T, Foster JL (2003) A prototype AMSR-E global snow area and snow depth algorithm. Geoscience and Remote Sensing, IEEE Trans Geosci Remote Sens 41: 230-242.

9. Dong J, Walker JP, Houser PR (2005) Factors affecting remotely sensed snow water equivalent uncertainty. Remote Sensing of Environment 97: 68-82.

10. Foster JL, Sun C, Walker JP, Kelly R, Chang A, et al. (2005) Quantifying the uncertainty in passive microwave snow water equivalent observations. Remote Sensing of Environment 94: 187-203.

11. Walker AE, Goodison BE (1995) Canadian Development and Use of Snow Cover Information from Passive Microwave Satellite Data. In: Choudhury BJ, Kerr YH, Njoku EG, Pampaloni P (Eds) Passive microwave remote sensing of land- atmosphere interactions. VSP, Utrecht, Tokyo, pp 245-262.

12. Derksen C, Brown R, Walker A (2004) Merging Conventional (1915-92) and Passive Microwave (1978-2002) Estimates of Snow Extent and Water Equivalent over Central North America. J Hydrometeorol 5: 850-861.

13. Josberger EG, Mognard NM (2002) A Passive Microwave Snow Depth Algorithm with a proxy for snow metamorphism. Hydrol Process 16: 1557-1568.

14. Azar AE, Lakhankar T, Ghedira H, Romanov P, Shahroudi N, et al. (2007) Using land cover data to improve estimated snow pack properties by microwave data. 21st Conference on Hydrology, 87th AMS Annual Meeting, San Antonio, TX.

15. Wiesmann A, Mätzler C (1999) Microwave emission model of layered snowpacks. Remote Sensing of Environment 70: 307-316.

16. Tsang L, Chen CT, Chang ATC, Guo J, Ding KH (2000) Dense media radiative transfer theory based on quasi-crystalline approximation with applications to microwave remote sensing of snow. Radio Science 35: 731-749.
17. Pulliainen J, Grandell J, Hallikainen M (1999) HUT snow emission model and its applicability to snow water equivalent retrieval. IEEE Trans. on Geoscience and Remote Sensing 37: 1378-1390.

18. Strum M, Holmgren J (1995) A seasonal Snow Cover Classification System fo Local to Global Application. J Clim 8: 1261-1283.

19. Hollinger JP, Lo R, Poe G, Savage, R, Pierce J (1987) Special Sensor Microwave/Imager user's guide. Naval Research Laboratory, Washington, D.C

20. Prigent C, Rossow WB, Matthews E (1997) Microwave land surface emissivities estimated from SSM/I observations. J Geophys Res 102: 21867-21890.

21. Chang ATC, Foster JL, Kelly REJ, Josberger EG, Armstrong RL, et al. Analysis of Ground-Measured and Passive-Microwave-Derived Snow Depth Variations in Midwinter across the Northern Great Plains. J Hydrometeorol 6: 20-33.

22. Wegmuller U, Matzler C (1999) Rough Bare Soil Reflectivity Model. IEEE Trans. on Geoscience and Remote Sensing 37: 1391-1395.

23. Stotzer E, Wegmuller U, H"uppi R, Matzler C (1986) Dielectric and surface parameters related to microwave scatter and emission properties. Proc. IGARSS'86, ESA SP-254, Zurich, Switzerland, pp 599-603.

24. Tedesco M, Kim EJ (2006) Intercomparison of Electromagnetic Models for Passive Microwave Remote Sensing of Snow. IEEE Trans. on Geoscience and Remote Sensing 44: 2654-2666.

25. Azar AE, Seo D, Powell A, Khanbilvardi R (2008) Analysis and Estimation of Snowpack Properties Using CLPX Data. 22nd Conference on Hydrology, 88th AMS Annual Meeting, New Orleans, LA.

26. Grody NC (2008) Relationship between snow parameters and microwave satellite measurements: Theory compared with Advanced Microwave Sounding Unit observations from 23 to $150 \mathrm{GHz}$. Journal of Geophysical Research 113: D22108. 